\title{
PENERAPAN METODE SIMPLE ADDITIVE WEIGHTING PADA SISTEM PENDUKUNG KEPUTUSAN PENENTUAN BEASISWA DAN REKOMENDASI MAGANG
}

\author{
Dinar Ajeng Kristiyanti ${ }^{1)}$ \\ ${ }^{1}$ Program Studi Teknologi Informasi Fakultas Teknik dan Informatika, Universitas Bina Sarana Informatika, \\ J1. Kramat Raya No. 98, Senen, Jakarta Pusat, Indonesia \\ Co Responden Email: dinar.dak@bsi.ac.id
}

Article history

Received June 14, 2021

Revised June 25, 2021

Accepted June 30, 2021

Available online June 30, 2021

\section{Keywords}

Decision Support System Internship Recommendation, Scholarships,

Simple Additive Weighting, Student.

\section{Riwayat}

Diterima 14 Juni 2021

Revisi 25 Juni 2021

Disetujui 30 Juni 2021

Terbit 30 Juni 2021

Kata Kunci

Sistem Penunjang Keputusan, Rekomendasi Magang

Beasiswa,

Simple Additive Weighting, Pelajar

\begin{abstract}
In educational institutions such as universities, scholarships and apprenticeship programs are mandatory, likewise at Trisakti University. Students who receive scholarships must meet predetermined criteria. The problem that often occurs is the provision of scholarships and inappropriate apprenticeship opportunities. The application of the decision support system used is Simple Additive Weighting (SAW) method with Multiple Attribute Decision Making (FMADM) is expected to help the university in determining outstanding students who are entitled to receive scholarships and internship recommendations by assessing each student, looking for a weighted addition of the rating performance on each alternative on all attributes. This is useful for making it easier for decision makers related to the problem of selecting outstanding students, so that students who are most worthy of an award will be found in the form of scholarships or recommendations for internships using the criteria for Student Activity Portfolio Aspects, Mastery of English, Creative Ideas Scientific Writing, and National Insights. Based on the results of calculations using the Simple Additive Weighting method by taking into account the existing criteria, students who get the highest score will be selected for scholarships and internship recommendations.
\end{abstract}

Abstrak
Di lembaga pendidikan seperti Universitas, beasiswa dan program magang
adalah hal yang harus ada, begitu juga di Universitas Trisakti. Mahasiswa yang
mendapat beasiswa tentu harus sesuai dengan kriteria yang telah ditentukan.
Permasalahan yang sering terjadi adalah pemberian beasiswa dan rekomendasi
kesempatan magang yang tidak tepat. Penerapan sistem pendukung keputusan
menggunakan metode Simple Additive Weighting (SAW) dengan Multiple
Attribute Decision Making (FMADM) diharapkan dapat membantu pihak
Universitas dalam menentukan mahasiswa berprestasi yang berhak menerima
beasiswa dan rekomendasi magang dengan menilai setiap mahasiswa, mencari
penambahan bobot rating kinerja pada setiap alternatif di semua atribut. Hal ini
berguna untuk memudahkan pengambil keputusan yang terkait dengan masalah
pemilihan mahasiswa berprestasi, sehingga akan didapatkan mahasiswa yang
paling layak diberi penghargaan berupa beasiswa atau pun rekomendasi
kesempatan magang menggunakan kriteria Aspek Portfolio Kegiatan
Mahasiswa, Penguasaan Bahasa Inggris, Karya Tulis Ilmiah Gagasan Kreatif,
Wawasan Kebangsaan. Hasil perhitungan menggunakan metode Simple
Additive Weighting dengan memperhatikan kriteria yang ada maka mahasiswa
yang memperoleh nilai tertinggi.


(Munthafa \& Mubarok, 2017). Mahasiswa yang cerdas dan berprestasi juga sudah seharusnya diberikan motivasi dari prestasi yang dimilikinya salah satunya adalah beasiswa. Beasiswa diberikan untuk membantu mahasiswa dalam menempuh studinya. Selain beasiswa, mahasiswa yang berprestasi juga dapat direkomendasikan untuk masuk dalam program magang misalnya menjadi asisten dosen, staf ahli ataupun menjadi dosen pengganti. Menurut (Ismail et al., 2018) aspek terpenting dalam program magang adalah menyiapkan lulusan calon pendidik yang profesional dari kemampuannya mengenali, mengamati sampai dengan dapat berdiri menjadi seorang pengajar maupun seorang profesional.

Seperti halnya pada Universitas Trisakti dalam menentukan mahasiswa berprestasi masih belum menggunakan sistem berbasis komputer yang menunjang keputusan dalam seleksinya seperti pemilihan yang seleksinya melalui bagian atau unit di Universitas dengan cara memberikan data pada formulir berupa kertas yang berisi daftar nama dan nilai kepada pihak mitra kerjasama untuk dipilih tanpa menggunakan sistem pendukung keputusan. Begitupun dengan pemilihan mahasiswa magang masih menggunakan media kertas yakni dengan cara mengisi formulir pendaftaran dan mahasiswa terbaik dipilih berdasarkan kesimpulan subjektif dari data mahasiswa yang terdaftar. Dengan jumlah mahasiswa yang cukup banyak, maka dibutuhkan sebuah Sistem Pendukung Keputusan (SPK) yang akan membantu pihak Universitas, unit ataupun biro dalam menentukan siapa yang berhak untuk menerima beasiswa dan rekomendasi magang agar keputusan tersebut dapat diambil dengan cepat dan akurat serta objektif bagi yang menerimanya.

\section{METODE PENELITIAN}

Sistem pendukung keputusan (SPK) itu sendiri adalah pengambilan keputusan yang dilakukan untuk menyelesaikan masalah yang dihadapi dengan memulai satu alternatif pemecahan masalah terbaik dengan berdasarkan pertimbangan-pertimbangan (kriteria) tertentu. Menurut (Stevanus et al., 2018), SPK adalah suatu sistem berbasis komputer yang menghasilkan berbagai alternatif keputusan untuk membantu manajemen dalam menangani berbagai permasalahan. Menurut (Abdul Khadir, 2014), pengambilan keputusan harus dilakukan secara sistematis, kemudian mengumpulkan fakta-fakta, kemudian ada penentuan yang matang dari alternatif yang dihadapi, dan selanjutnya mengambil tindakan yang menurut perhitungan merupakan tindakan yang paling tepat. Selain itu menurut (Nofriansyah, 2014), SPK digunakan dalam pengambilan keputusan serta bagaimana pola-pola menyelesaikan masalah dengan beberapa metode pemecahan masalah. Perkembangan sistem pendukung keputusan saat ini banyak memunculkan beberapa metode diantarannya Technique for Others Preference by Similarity to Ideal Solution (TOPSIS) (Ikmah \& Widawati, 2021)(Katili et al., 2021), Analitycal Hierarchy Process (AHP) (Kristiyanti \& Pangemanan, 2020) (Munthafa \& Mubarok, 2017), Simple Additive Weighting (SAW) (Sembiring \& Sibuea, 2019)(Susanto \& Patawaran, 2019)(Yasdomi et al., 2019)(Nurhasanah et al., 2020), Weighted Product (Hindayati \& Hirzi Nur, 2017), Moora (Muharsyah et al., 2018), Profile Matching (Kristiyanti, 2017) dan lain sebagainya. Salah satu metode yang sering dipakai yakni Simple Additive Weighting (SAW).

Penelitian pemilihan mahasiswa berprestasi dan rekomendasi mahasiswa magang dengan menerapkan SPK yang dipakai untuk mendukung pengambilan keputusan dalam suatu organisasi atau instansi yang terbukti memiliki kinerja yang sangat efektif terhadap data-data yang nilainya berupa kisaran dalam jangkauan nilai tertentu (Muharsyah et al., 2018). Cara penyelesaian masalah menggunakan metode penghitungan tertimbang atau metode yang memberikan kriteria tertentu sehingga setiap nilai dari jumlah bobot hasil yang diperoleh akan menjadi keputusan akhir (Frieyadie, 2016). Penelitian ini bertujuan membantu Universitas dalam memilih mahasiswa yang berhak menerima beasiswa dan rekomendasi magang. Hasil Penelitian (Hidayat et al., 2020) menyimpulkan bahwa dari data calon penerima beasiswa yang telah dicocokkan antara alternatif dan kriteria yang telah dibobotkan, maka dari hasil perangkingan metode SAW lebih mendekati keakuratan.

Menurut (Frieyadie, 2016) dalam metode SAW mencari penjumlahan terbobot dari rating kinerja pada setiap alternatif pada semua 
atribut. Menurut metode ini adalah metode penghitungan tertimbang atau metode yang memberikan kriteria tertentu ditimbang sehingga setiap nilai dari jumlah bobot hasil yang diperoleh akan menjadi keputusan akhir. Menurut (Pramana et al., 2019) Metode ini mengharuskan pembuat keputusan menentukan bobot bagi setiap atribut atau kriteria. Kelebihan SAW ada pada konsistensi matriks dan proses perhitungannya dibandingkan dengan metode lainnya.

Metode pengumpulan data merupakan faktor penting demi keberhasilan penelitian. Hal ini berkaitan dengan bagaimana cara mengumpulkan data, siapa sumbernya dan alat apa saja yang digunakan. Metode pengumpulan data yang dilakukan dalam penelitian ini terbagi menjadi 2 (dua) cara yaitu:

1. Cara pertama dengan cara observasi langsung, wawancara, kuisioner untuk mendapatkan data primer. Data primer adalah data yang dikumpulkan langsung oleh peneliti dari pengisian kuesioner responden dan bukan berasal dari pengumpulkan data yang pernah dilakukan sebelumnya. Data primer adalah data yang diperoleh dari sumbersumber asli. Sumber asli di sini diartikan sebagai sumber pertama dari mana data tersebut diperoleh. Dalam pengumpulan data primer dalam penelitian ini menggunakan metode observasi dan wawancara.

2. Sedangkan untuk data sekunder berasal dari mengumpulkan dan mengidentifikasi serta mengolah data tertulis berbentuk buku dan jurnal yang berkaitan dengan penelitian.

Populasi adalah suatu kumpulan subjek dan variable penelitian (poningsih, 2020). Populasi dari penelitian ini yaitu mahasiswa dari 9 (sembilan) Fakultas di lingkup Universitas yang mengikuti kegiatan pemilihan mahasiswa berprestasi di tingkat Universitas 30 Orang.

Sampel disebut juga contoh. Berdasarkan pakar atau ahli, sampel adalah sebagian dari populasi yang karakteristiknya hendak diteliti. Untuk menentukan ukuran sampel dari populasi, peneliti menggunakan rumus Slovin sebagai berikut:

$\mathrm{n}=\frac{\mathrm{N}}{1+\mathrm{Ne}^{2}}$
Keterangan:

$\mathrm{n}$ : Ukuran sampel

$\mathrm{N}$ : Populasi

e : Prosentasi kelonggaran ketidakterikatan karena kesalahan pengamilan sampelyang masih diinginkan)

Dalam pengambilan data sampel ini, maka hasil yang diperoleh melalui perhitungan dengan nilai krisis (batas ketelitian) sebesar 20\% sebagai berikut:

$$
\begin{aligned}
& \mathrm{n}=\frac{\mathrm{N}}{1+\left(\mathrm{N} \mathrm{x}^{2}\right)} \\
& \mathrm{n}=\frac{30}{1+30(0.2)^{2}} \\
& \mathrm{n}=\frac{30}{2,2}=13,6
\end{aligned}
$$

Berdasarkan hasil tersebut, maka jumlah sampel minimal adalah sebanyak 14 orang. Langkah menggunakan metode SAW, sebagai berikut:

1. Menentukan alternatif, yaitu Ai

2. Menentukan kriteria yang akan dijadikan acuan dalam pengambilan keputusan, yaitu $\mathrm{Cj}$

3. Menentukan bobot preferansi atau tingkat kepentingan (W) setiap kriteria.

4. Memberikan nilai rating kecocokan setiap alternatif pada setiap kriteria.

5. Membuat matriks keputusan (X) yang dibentuk dari tabel rating kecocokan dari setiap alternatif pada setiap kriteria. Nilai $X$ setiap alternatif (Ai) pada setiap kriteria (Cj) yang sudah ditentukan, dimana $i=1,2$, $\ldots, m$ dan $j=1,2, \ldots, n$.

6. Melakukan proses normalisasi matriks keputusan (X) ke suatu skala yang dapat diperbandingkan dengan semua ranting alternatif yang ada.

$R_{i j} \frac{x_{y}}{\operatorname{Max} x_{i j}}$

7. Hasil dari normalisasi matriks (Rij) membentuk matriks ternormalisasi (R).

8. Hasil akhir nilai preferensi (Vi ) diperoleh dari penjumlahan dari perkalian elemen baris matriks ternormalisasi (R) dengan bobot preferensi (W) yang bersesuaian dengan elemen kolom matriks (R).

$v i=\sum_{j=1}^{n} \boldsymbol{r}_{i j}$

9. Proses perangkingan diperoleh berdasarkan alternatif yang memiliki nilai total terbesar sampai terendah sebagai penentuan Mahasiswa Berprestasi. 


\section{HASIL DAN PEMBAHASAN}

Ada beberapa langkah untuk malakukan perhitungan menentukan mahasiswa berprestasi menggunakan metode Simple Additive Weighting (SAW) antara lain:

1. Data alternatif yakni mahasiswa yang didapat dari penilaian responden. Data yang diambil digunakan dalam perhitungan analisis ini. Langkah kesatu menentukan alternatif, yaitu $A_{i}$. Berikut adalah data alternatif mahasiswa yang digunakan dalam perhitungan dapat dilihat pada Tabel 1.

Tabel 1. Data alternatif mahasiswa

\begin{tabular}{|c|c|c|c|c|c|}
\hline \multirow[b]{2}{*}{ No. } & \multirow[b]{2}{*}{ Nama Mahasiswa } & \multicolumn{4}{|c|}{ Kriteria } \\
\hline & & $\begin{array}{c}\text { Portofolio Kegiatan } \\
\text { Mahasiswa }\end{array}$ & $\begin{array}{c}\text { Penguasaan } \\
\text { Bahasa Inggris }\end{array}$ & $\begin{array}{c}\text { Karya Tulis Ilmiah } \\
\text { Gagasan Kreatif }\end{array}$ & $\begin{array}{c}\text { Wawasan } \\
\text { Kebangsaan }\end{array}$ \\
\hline 1 & Ahmad Sabirin & 80 & 90 & 80 & 92 \\
\hline 2 & Andi Setyo & 80 & 80 & 75 & 75 \\
\hline 3 & Rifki Pandu Kusuma & 85 & 91 & 94 & 92 \\
\hline 4 & Maulidia Hanafi & 85 & 85 & 82 & 80 \\
\hline 5 & Lejla Amira Syahdan & 84 & 78 & 85 & 85 \\
\hline 6 & Raynaldi Kusuma & 74 & 86 & 70 & 70 \\
\hline 7 & Felicia Setyawati & 78 & 80 & 75 & 80 \\
\hline 8 & Trisno Handoyo & 70 & 80 & 80 & 75 \\
\hline & M. Rhafii & & & & \\
\hline 9 & Prawiraputra & 75 & 78 & 79 & 82 \\
\hline 10 & Anasthesia Karunia & & & & \\
\hline & Charles & 84 & 79 & 76 & 82 \\
\hline 11 & Inggrid Kumalasari & 70 & 75 & 80 & 91 \\
\hline 12 & Komang Arya Partha & & & & \\
\hline 12 & Wijaya & 85 & 94 & 88 & 79 \\
\hline 13 & Ribka Emmanauli & 80 & 81 & 70 & 80 \\
\hline 14 & Prasetya Argawiguna & 70 & 80 & 70 & 75 \\
\hline
\end{tabular}

2. Kriteria dan Bobot

Berikut merupakan kriteria yang dibutuhkan untuk pengambilan keputusan, berdasarkan parameter dalam menentukan pemilihan mahasiswa berprestasi. Adapun kriteria yang telah ditentukan pada Tabel 2 sebagai berikut:

Tabel 2. Kriteria

\begin{tabular}{|c|c|}
\hline Kriteria C & Keterangan \\
\hline $\mathrm{C}_{1}$ & $\begin{array}{c}\text { Portfolio Kegiatan } \\
\text { Mahasiswa }\end{array}$ \\
\hline $\mathrm{C}_{2}$ & $\begin{array}{c}\text { Penguasaan Bahasa } \\
\text { Inggris }\end{array}$ \\
\hline $\mathrm{C}_{3}$ & $\begin{array}{c}\text { Karya Tulis Ilmiah } \\
\text { Gagasan Kreatif }\end{array}$ \\
\hline $\mathrm{C}_{4}$ & Wawasan Kebangsaan \\
\hline
\end{tabular}

Selanjutnya menentukan Nilai Bobot yang akan dijadikan acuan dalam pengambilan keputusan, yaitu $C_{j}$.

a. Nilai Matematika (C1)

Nilai Bobot Portfolio Kegiatan

Mahasiswa ditunjukkan pada Tabel 3 berikut:

\begin{tabular}{ccc}
\multicolumn{3}{c}{ Tabel 3. Nilai portfolio kegiatan mahasiswa } \\
\hline Keterangan & $\begin{array}{c}\text { Bilangan } \\
\text { Fuzzy }\end{array}$ & $\begin{array}{c}\text { Nilai } \\
\text { Bobot }\end{array}$ \\
\hline $\begin{array}{c}\text { Kurang Baik } \\
\text { (30-50) }\end{array}$ & Rendah (R) & 1 \\
$\begin{array}{c}\text { Cukup Baik (51- } \\
\text { 79) }\end{array}$ & Cukup (C) & 2 \\
$\begin{array}{c}\text { Baik (80-90) } \\
\text { Sangat Baik (91- } \\
\text { 100) }\end{array}$ & $\begin{array}{c}\text { Tinggi (T) } \\
\text { Sangat Tinggi } \\
\text { (ST) }\end{array}$ & 3 \\
\hline
\end{tabular}

b. Nilai Penguasaan Bahasa Inggris (C2)

Nilai dan Bobot Penguasaan Bahasa Inggris ditunjukkan pada Tabel 4 berikut:

Tabel 4. Nilai penguasaan bahasa inggris

\begin{tabular}{ccc}
\hline Keterangan & Bilangan Fuzzy & $\begin{array}{c}\text { Nilai } \\
\text { Bobot }\end{array}$ \\
\hline $\begin{array}{c}\text { Kurang Baik (30- } \\
\text { 50) }\end{array}$ & Rendah (R) & 1 \\
$\begin{array}{c}\text { Cukup Baik (51- } \\
\text { 79) }\end{array}$ & 2 \\
Cukup (C) & 3 \\
$\begin{array}{c}\text { Baik (80-90) } \\
\text { Tingat Baik (91- }\end{array}$ & $\begin{array}{c}\text { Sangat Tinggi } \\
\text { (ST) }\end{array}$ & 4 \\
\hline
\end{tabular}


c. Nilai Karya Tulis Ilmiah Gagasan

Kreatif (C3)

Nilai dan Bobot Karya Tulis Ilmiah

Gagasan Kreatif ditunjukkan pada

Tabel 5 berikut:

Tabel 5. Nilai karya tulis ilmiah gagasan kreatif

\begin{tabular}{ccc}
\hline Keterangan & $\begin{array}{c}\text { Bilangan } \\
\text { Fuzzy }\end{array}$ & $\begin{array}{c}\text { Nilai } \\
\text { Bobot }\end{array}$ \\
\hline $\begin{array}{c}\text { Kurang Baik (30- } \\
\text { 50) }\end{array}$ & Rendah (R) & 1 \\
Cukup Baik (51- & Cukup (C) & 2 \\
$79)$ & Tinggi (T) & 3 \\
Baik (80-90) & $\begin{array}{c}\text { Sangat Tinggi } \\
\text { (ST) }\end{array}$ & 4 \\
Sangat Baik (91- & \\
100) & & \\
\hline
\end{tabular}

d. Nilai Wawasan Kebangsaan (C4)

Nilai dan Bobot Karya Tulis

Ilmiah Gagasan Kreatif

ditunjukkan pada Tabel 6 berikut:

Tabel 6. Nilai wawasan kebangsaan

\begin{tabular}{ccc}
\hline Keterangan & Bilangan Fuzzy & $\begin{array}{c}\text { Nilai } \\
\text { Bobot }\end{array}$ \\
\hline $\begin{array}{c}\text { Kurang Baik } \\
\text { (30-50) }\end{array}$ & Rendah (R) & 1 \\
$\begin{array}{c}\text { Cukup Baik (51- } \\
\text { 79) }\end{array}$ & Cukup (C) & 2 \\
Baik (80-90) & Tinggi (T) & 3 \\
$\begin{array}{c}\text { Sangat Baik (91- } \\
\text { 100) }\end{array}$ & Sangat Tinggi (ST) & 4 \\
\hline
\end{tabular}

3. Bobot Preferensi (W)

Langkah ketiga ketiga menentukan bobot preferensi atau tingkat kepentingan (W) setiap kriteria. Bobot kriteria yang digunakan dalam menentukan mahasiswa berprestasi ditunjukkan pada Tabel 7 sebagai berikut:

Tabel 7. Tingkat kepentingan (w)

\begin{tabular}{|c|c|c|}
\hline Kriteria (C) & $\begin{array}{c}\text { Bobot } \\
\text { W }\end{array}$ & Keterangan \\
\hline $\begin{array}{l}C_{1}=\text { Nilai Portfolio } \\
\text { Kegiatan Mahasiswa }\end{array}$ & 3 & $\begin{array}{l}\text { Sangat } \\
\text { Tinggi }\end{array}$ \\
\hline $\begin{array}{c}\mathrm{C}_{2}=\text { Nilai Penguasaan } \\
\text { Bahasa Inggris }\end{array}$ & 3 & $\begin{array}{l}\text { Sangat } \\
\text { Tinggi }\end{array}$ \\
\hline $\begin{array}{c}\mathrm{C}_{3}=\text { Nilai Karya Tulis } \\
\text { Ilmiah Gagasan } \\
\text { Kreatif }\end{array}$ & 2 & Tinggi \\
\hline $\begin{array}{c}\mathrm{C}_{4}=\text { Nilai Wawasan } \\
\text { Kebangsaan }\end{array}$ & 2 & Tinggi \\
\hline
\end{tabular}

4. Nilai Rating Kecocokan Setiap Alternatif pada Setiap Kriteria
Langkah keempat menentukan rating kecocokan setiap alternatif pada setiap kriteria yang telah ditentukan di atas ditunjukkan pada Tabel 8 sebagai berikut:

Tabel 8. Rating kecocokan alternatif

\begin{tabular}{|c|c|c|c|c|c|}
\hline \multirow[b]{2}{*}{ No. } & \multirow{2}{*}{$\begin{array}{l}\text { Alternatif } \\
\text { (Nama } \\
\text { Mahasisw } \\
\text { a) }\end{array}$} & \multicolumn{4}{|c|}{ Kriteria } \\
\hline & & $\mathrm{C} 1$ & $\mathrm{C} 2$ & $\mathrm{C} 3$ & $\mathrm{C} 4$ \\
\hline 1 & A1 & 3 & 3 & 4 & 4 \\
\hline 2 & $\mathrm{~A} 2$ & 3 & 3 & 2 & 2 \\
\hline 3 & A3 & 3 & 4 & 4 & 4 \\
\hline 4 & A4 & 3 & 3 & 3 & 3 \\
\hline 5 & A5 & 3 & 4 & 2 & 3 \\
\hline 6 & A6 & 2 & 2 & 2 & 2 \\
\hline 7 & A7 & 3 & 3 & 2 & 3 \\
\hline 8 & A8 & 2 & 3 & 3 & 2 \\
\hline 9 & A9 & 2 & 2 & 2 & 3 \\
\hline 10 & A10 & 3 & 2 & 4 & 3 \\
\hline 11 & A11 & 2 & 2 & 3 & 4 \\
\hline 12 & A12 & 3 & 4 & 3 & 3 \\
\hline 13 & A13 & 3 & 3 & 3 & 4 \\
\hline 14 & A14 & 2 & 3 & 2 & 2 \\
\hline
\end{tabular}

5. Matriks Keputusan

Setelah nilai rating alternatif pada setiap kriteria ditentukan langkah kelima adalah membuat matriks keputusan (X) yang dibentuk dari tabel rating kecocokan dari setiap alternatif pada setiap kriteria. Nilai $X$ setiap alternatif $\left(\mathrm{A}_{\mathrm{i}}\right)$ pada setiap kriteria $\left(\mathrm{C}_{\mathrm{j}}\right)$ yang sudah ditentukan. Matriks keputusan pada penelitian ini dapat dilihat pada Tabel 9.

Tabel 9. Matriks keput
\begin{tabular}{llll}
3 & 3 & 4 & 4 \\
3 & 3 & 2 & 2 \\
3 & 4 & 4 & 4 \\
3 & 3 & 3 & 3 \\
3 & 4 & 2 & 3 \\
2 & 2 & 2 & 2 \\
3 & 3 & 2 & 3 \\
2 & 3 & 3 & 2 \\
2 & 2 & 2 & 3 \\
3 & 2 & 4 & 3 \\
2 & 2 & 3 & 4 \\
3 & 4 & 3 & 3 \\
3 & 3 & 3 & 4 \\
2 & 3 & 2 & 2 \\
\hline
\end{tabular}

6. Normalisasi Matriks Keputusan (X)

Langkah keenam melakukan proses normalisasi matriks keputusan (X) ke suatu skala yang dapat diperbandingkan dengan 
semua rating alternatif yang ada. Dengan bobot preferensi adalah 3, 3, 2 dan 2. Hasil normalisasi matriks keputusan $(\mathrm{X})$ dapat

$$
\boldsymbol{R}_{i j}=\frac{x_{i j}}{\operatorname{Max} x_{i j}}
$$
dilihat pada Tabel 10.

Tabel 10. Normalisasi matriks keputusan (x)

\begin{tabular}{ccc}
\hline Alternatif 1 & Alternatif 2 & Alternatif 3 \\
\hline $\mathrm{r} 11=3 / 3=1,00$ & $\mathrm{r} 21=3 / 3=1,00$ & $\mathrm{r} 31=3 / 3=1,00$ \\
$\mathrm{r} 12=3 / 4=0,75$ & $\mathrm{r} 22=3 / 4=0,75$ & $\mathrm{r} 32=4 / 4=1,00$ \\
$\mathrm{r} 13=4 / 4=1,00$ & $\mathrm{r} 23=2 / 4=0,50$ & $\mathrm{r} 33=4 / 4=1,00$ \\
$\mathrm{r} 14=4 / 4=1,00$ & $\mathrm{r} 24=2 / 4=0,50$ & $\mathrm{r} 34=4 / 4=1,00$ \\
\hline Alternatif 4 & Alternatif 5 & Alternatif 6 \\
\hline $\mathrm{r} 41=3 / 3=1,00$ & $\mathrm{r} 51=3 / 3=1,00$ & $\mathrm{r} 61=2 / 3=0,67$ \\
$\mathrm{r} 42=3 / 4=0,75$ & $\mathrm{r} 52=4 / 4=1,00$ & $\mathrm{r} 62=2 / 4=0,50$ \\
$\mathrm{r} 43=3 / 4=0,75$ & $\mathrm{r} 53=2 / 4=0,50$ & $\mathrm{r} 63=2 / 4=0,50$ \\
$\mathrm{r} 44=3 / 4=0,75$ & $\mathrm{r} 54=3 / 4=0,75$ & $\mathrm{r} 64=2 / 4=0,50$ \\
\hline Alternatif 7 & Alternatif 8 & Alternatif 9 \\
\hline $\mathrm{r} 71=3 / 3=1,00$ & $\mathrm{r} 81=2 / 3=0,67$ & $\mathrm{r} 91=2 / 3=0,67$ \\
$\mathrm{r} 72=3 / 4=0,75$ & $\mathrm{r} 82=3 / 4=0,75$ & $\mathrm{r} 92=2 / 4=0,50$ \\
$\mathrm{r} 73=2 / 4=0,50$ & $\mathrm{r} 83=3 / 4=0,75$ & $\mathrm{r} 93=2 / 4=0,50$ \\
$\mathrm{r} 74=3 / 4=0,75$ & $\mathrm{r} 84=2 / 4=0,50$ & $\mathrm{r} 94=3 / 4=0,75$ \\
\hline Alternatif 10 & Alternatif 11 & Alternatif 12 \\
\hline $\mathrm{r} 71=3 / 3=1,00$ & $\mathrm{r} 81=2 / 3=0,67$ & $\mathrm{r} 91=3 / 3=1,00$ \\
$\mathrm{r} 72=2 / 4=0,50$ & $\mathrm{r} 82=2 / 4=0,50$ & $\mathrm{r} 92=4 / 4=1,00$ \\
$\mathrm{r} 73=4 / 4=1,00$ & $\mathrm{r} 83=3 / 4=0,75$ & $\mathrm{r} 93=3 / 4=0,75$ \\
$\mathrm{r} 74=3 / 4=0,75$ & $\mathrm{r} 84=4 / 4=1,00$ & $\mathrm{r} 94=3 / 4=0,75$ \\
\hline Alternatif 13 & Alternatif 14 & \\
\hline $\mathrm{r} 71=3 / 3=1,00$ & $\mathrm{r} 81=2 / 3=0,67$ & \\
$\mathrm{r} 72=3 / 4=0,75$ & $\mathrm{r} 82=3 / 4=0,75$ & \\
$\mathrm{r} 73=3 / 4=0,75$ & $\mathrm{r} 83=2 / 4=0,50$ & \\
$\mathrm{r} 74=4 / 4=1,00$ & $\mathrm{r} 84=2 / 4=0,50$ & \\
\hline
\end{tabular}

7. Matriks Ternormalisasi (R)

Hasil dari normalisasi matriks $\left(\mathrm{R}_{\mathrm{ij}}\right)$ membentuk matriks ternormalisasi $(\mathrm{R})$. Matriks ternormalisasi (R) dapat dilihat pada Tabel 11.

Tabel 11. Matriks ternormalisasi $(R)$

\begin{tabular}{|llll|}
\hline 1.00 & 0.75 & 1.00 & 1.00 \\
1.00 & 0.75 & 0.50 & 0.50 \\
1.00 & 1.00 & 1.00 & 1.00 \\
1.00 & 0.75 & 0.75 & 0.75 \\
1.00 & 1.00 & 0.50 & 0.75 \\
0.67 & 0.50 & 0.50 & 0.50 \\
1.00 & 0.75 & 0.50 & 0.75 \\
0.67 & 0.75 & 0.50 & 0.75 \\
0.67 & 0.75 & 0.75 & 0.50 \\
1.00 & 0.50 & 1.00 & 0.75 \\
0.67 & 0.50 & 0.75 & 1.00 \\
1.00 & 1.00 & 0.75 & 0.75 \\
1.00 & 0.75 & 0.75 & 1.00 \\
0.67 & 0.75 & 0.50 & 0.50 \\
\hline
\end{tabular}

8. Nilai Preferensi $\left(\mathrm{V}_{\mathrm{i}}\right)$

Langkah kedelapan menghitung hasil akhir nilai preferensi $\left(\mathrm{V}_{\mathrm{i}}\right)$ diperoleh dari penjumlahan dari perkalian elemen baris matriks ternormalisasi (R) dengan bobot preferensi (W) yang bersesuaian dengan elemen kolom matriks (R) dapat dilihat pada Tabel 12 dengan rumus (4) di bawah ini.

$$
v i=\sum_{j=1}^{n} r_{i j}
$$

\begin{tabular}{|c|c|}
\hline $\mathrm{V}_{1}=$ & {$[(3 \times 1,00)+(3 \times 0,75)+(2 \times 1,00)+$} \\
\hline $\mathrm{V}_{2}=$ & $\begin{array}{l}(2 \times 1,00)]=9.25 \\
{[(3 \times 1,00)+(3 \times 0,75)+(2 \times 0,50)+} \\
(2 \times 0,50)]=7.25\end{array}$ \\
\hline $\mathrm{V}_{3}=$ & $\begin{array}{l}{[(3 \times 1,00)+(3 \times 1,00)+(2 \times 1,00)+} \\
(2 \times 1,00)]=10.00\end{array}$ \\
\hline $\mathrm{V}_{4}=$ & $\begin{array}{l}{[(3 \times 1,00)+(3 \times 0,75)+(2 \times 0,75)+} \\
(2 \times 0,75)]=8.25\end{array}$ \\
\hline $\mathrm{V}_{5}=$ & $\begin{array}{l}{[(3 \times 1,00)+(3 \times 1,00)+(2 \times 0,50)+} \\
(2 \times 0,75)]=8.50\end{array}$ \\
\hline $\mathrm{V}_{6}=$ & $\begin{array}{l}{[(3 \times 0,67)+(3 \times 0,50)+(2 \times 0,50)+} \\
(2 \times 0,50)]=5.50\end{array}$ \\
\hline $\mathrm{V}_{7}=$ & $\begin{array}{l}{[(3 \times 1,00)+(3 \times 0,75)+(2 \times 0,50)+} \\
(2 \times 0,75)]=7.75\end{array}$ \\
\hline $\mathrm{V}_{8}=$ & $\begin{array}{l}{[(3 \times 0,67)+(3 \times 0,75)+(2 \times 0,75)+} \\
(2 \times 0,50)]=6.75\end{array}$ \\
\hline
\end{tabular}

Tabel 12. Nilai preferensi $\left(V_{i}\right)$ 


$\begin{array}{ll}\mathrm{V}_{9}= & {[(3 \times 0,67)+(3 \times 0,50)+(2 \times 0,50)+} \\ & (2 \times 0,75)]=6.00 \\ \mathrm{~V}_{10}=\quad[(3 \times 1,00+(3 \times 0,50)+(2 \times 1,00)+ \\ \\ (2 \times 0,75)]=8.00 \\ \mathrm{~V}_{11}=\quad[(3 \times 1,00)+(3 \times 0,75)+(2 \times 1,00)+ \\ (2 \times 1,00)]=7.00\end{array}$

Di bawah ini adalah hasil tabel pengujian dimana nilai awal penilaian mahasiswa diproses menggunakan metode Simple Additive Weighting (SAW) dan mendapatkan nilai hasil akhir dalam perhitungan seperti di atas, berikut dapat dilihat pada Tabel 13 di bawah ini.

Tabel 13. Hasil pengujian dengan metode saw

\begin{tabular}{|c|c|c|c|c|c|c|}
\hline \multirow[b]{2}{*}{ No. } & \multirow[b]{2}{*}{$\begin{array}{c}\text { Nama } \\
\text { Mahasiswa }\end{array}$} & \multicolumn{4}{|c|}{ Kriteria } & \multirow[b]{2}{*}{ Hasil } \\
\hline & & $\mathrm{C} 1$ & $\mathrm{C} 2$ & $\mathrm{C} 3$ & $\mathrm{C} 4$ & \\
\hline 1 & Ahmad Sabirin & 1.00 & 0.75 & 1.00 & 1.00 & 9.25 \\
\hline 2 & Andi Setyo & 1.00 & 0.75 & 0.50 & 0.50 & 7.25 \\
\hline 3 & Rifki Pandu Kusuma & 1.00 & 1.00 & 1.00 & 1.00 & 10.00 \\
\hline 4 & Maulidia Hanafi & 1.00 & 0.75 & 0.75 & 0.75 & 8.25 \\
\hline 5 & Lejla Amira Syahdan & 1.00 & 1.00 & 0.50 & 0.75 & 8.50 \\
\hline 6 & Raynaldi Kusuma & 0.67 & 0.50 & 0.50 & 0.50 & 5.50 \\
\hline 7 & Felicia Setyawati & 1.00 & 0.75 & 0.50 & 0.75 & 7.75 \\
\hline 8 & Trisno Handoyo & 0.67 & 0.75 & 0.75 & 0.50 & 6.75 \\
\hline 9 & M. Rhafii Prawiraputra & 0.67 & 0.50 & 0.50 & 0.75 & 6.00 \\
\hline 10 & $\begin{array}{l}\text { Anasthesia Karunia } \\
\text { Charles }\end{array}$ & 1.00 & 0.50 & 1.00 & 0.75 & 8.00 \\
\hline 11 & Inggrid Kumalasari & 0.67 & 0.50 & 0.75 & 1.00 & 7.00 \\
\hline 12 & $\begin{array}{l}\text { Komang Arya Partha } \\
\text { Wijaya }\end{array}$ & 1.00 & 1.00 & 0.75 & 0.75 & 9.00 \\
\hline 13 & Ribka Emmanauli & 1.00 & 0.75 & 0.75 & 1.00 & 8.75 \\
\hline 14 & Prasetya Argawiguna & 0.67 & 0.75 & 0.50 & 0.50 & 6.25 \\
\hline
\end{tabular}

Berdasarkan tabel hasil pengujian dengan metode SAW di atas, maka Nilai terbesar ada pada V3 sehingga alternatif A3 (Rifki Pandu Kusuma) adalah alternatif yang terpilih sebagai alternatif yang terbaik dengan hasil akhir $=10$.

\section{KESIMPULAN}

Dari hasil penelitian yang telah dilakukan, maka peneliti dapat menarik kesimpulan dari pembahasan penelitian yang telah dilakukan, diantaranya:

1. Sistem yang dibangun dapat membantu Biro kemahasiswaan dan Pusat Karir dalam menentukan mahasiswa berprestasi untuk diberikan beasiswa dan kesempatan magang terhadap mahasiswa berprestasi khususnya pada Universitas Trisakti.

2. Sistem Pendukung Keputusan dengan metode SAW mampu mempercepat proses pemilihan mahasiswa berprestasi dengan hasil yang valid dan akurat.

3. Penentuan pemilihan beasiswa dan rekomendasi magang mahasiswa berprestasi mahasiswa dilakukan berdasarkan kriteria yang telah ditentukan.
4. Bobot yang diberikan pada setiap kriteria mempengaruhi hasil akhir penentuan mahasiswa berprestasi. Perubahan nilai bobot pada suatu kriteria juga akan mempengaruhi hasil akhir perhitungan.

5. Dari perhitungan menggunakan metode SAW didapatkan Mahasiswa Rifki Pandu Kusuma sebagai mahasiswa berprestasi dengan raihan nilai 10 dan berhak mendapatkan beasiswa, rekomendasi kesempatan magang.

\section{REFERENSI}

Abdul Khadir. (2014). Sistem Pendukung Keputusan. In Sistem Pendukung Keputusan.

Frieyadie, F. (2016). PENERAPAN METODE SIMPLE ADDITIVE WEIGHT (SAW) DALAM SISTEM PENDUKUNG KEPUTUSAN PROMOSI KENAIKAN JABATAN. Jurnal Pilar Nusa Mandiri. https://doi.org/10.33480/pilar.v12i1.257

Hidayat, T., Friana, B., \& Ghofur, K. (2020). Sistem Pendukung Keputusan Terhadap Penyeleksian Calon Mahasiswa Penerima Beasiswa Peningkatan Prestasi Akademik (BPPA) Dengan Metode Simple Additive Weighting (SAW) dan Weighted Product 
(WP). Jutis (Jurnal Teknik Informatika), $8(1)$, $119-134$ https://doi.org/https://doi.org/10.33592/jut is.v8i1.707

Hindayati, M., \& Hirzi Nur, H. (2017). Sistem Pendukung Keputusan Penentuan Mahasiswa Berprestasi di Universitas Muhammadiyah Purwokerto Menggunakan Metode Weighted Product ( WP ). Juita, 5(1), 51-61.

Ikmah, I., \& Widawati, A. S. (2021). Sistem Pendukung Keputusan Penentuan Beasiswa Mahasiswa Berprestasi Menggunakan Metode Topsis. CSRID (Computer Science Research and Its Development Journal), 12(1), 34. https://doi.org/10.22303/csrid.12.1.2020.3 4-41

Ismail, I., Hasan, H., \& Musdalifah, M. (2018). Pengembangan Kompetensi Mahasiswa Melalui Efektivitas Program Magang Kependidikan. Edumaspul - Jurnal Pendidikan.

https://doi.org/10.33487/edumaspul.v2i1.4 8

Katili, M. Z., Amali, L. N., \& Tuloli, M. S. (2021). Impelementasi Metode AHPTOPSIS Dalam Sistem Pendukung Rekomendasi Mahasiswa Berprestasi. 3(1), 1-10. https://doi.org/10.37905/jji.v2i2.10246

Kristiyanti, D. A. (2017). Sistem Pendukung Keputusan Seleksi Karyawan Untuk Jabatan Tertentu Dengan Pendekatan Analisa Gap Profile Matching. Paradigma - Jurnal Komputer Dan Informatika, 19(1), 20-29. https://doi.org/10.31294/P.V19I1.1502

Kristiyanti, D. A., \& Pangemanan, G. W. (2020). Decision Support System in Determining the Best Judo Athlete Using Ahp Method. Jurnal Pilar Nusa Mandiri, 16(1), 45-52. https://doi.org/10.33480/pilar.v16i1.919

Muharsyah, A., Hayati, S. R., Setiawan, M. I., Nurdiyanto, H., \& Yuhandri. (2018). Sistem Pendukung Keputusan Penerimaan Jurnalis Menerapkan MultiObjective Optimization On The Basis Of Ratio Analysis (MOORA). Jurnal Riset Komputer (JURIKOM). https://doi.org/10.30645/j-sakti.v2i2.79

Munthafa, A., \& Mubarok, H. (2017). Penerapan
Metode Analytical Hierarchy Process Dalam Sistem Pendukung Keputusan Penentuan Mahasiswa Berprestasi. Jurnal Siliwangi, 3(2), 192-201.

Nofriansyah, D. (2014). Konsep Data Mining vs Sistem Pendukung Keputusan.

Nurhasanah, E. K., Abadi, S., \& Sukamto, P. (2020). Sistem Pendukung Keputusan Pemilihan Mahasiswa Berprestasi dengan Metode Simple Additive Weighting. TEKNOSAINS: Jurnal Sains, Teknologi Dan Informatika, 7(2), 107-118.

poningsih. (2020). Sistem Pendukung Keputusan: Penerapan. Yayasan Kita Menulis.

Pramana, S., Hartati, R. S., \& Divayana, Y. (2019). Analisis Metode Sistem Pendukung Keputusan Pemilihan Waktu Terbaik Perubahan Harga Dinamis Hotel. Majalah Ilmiah Teknologi Elektro. https://doi.org/10.24843/mite.2019.v18i02 .p02

Sembiring, M. A., \& Sibuea, M. F. larasati. (2019). Penerapan Metode Saw Untuk Pemberian Beasiswa Mahasiswa Berprestasi. 4307(February), 12-15.

Stevanus, R., Handayani, R. I., \& Kristiyanti, D. A. (2018). Sistem Pendukung Keputusan Pemberian Bonus Karyawan Menggunakan Metode Ahp Pada Rumah Sakit Buah Hati Ciputat. Sistem Pendukung Keputusan Pemberian Bonus Karyawan Menggunakan Metode Ahp Pada Rumah Sakit Buah Hati Ciputat, 2(2), 1-8. http://jurnal.una.ac.id/index.php/jurti/articl e/view/42/39

Susanto, \& Patawaran, N. (2019). Sistem Pendukung Keputusan Mahasiswa Berprestasi Menggunakan Metode Saw Pada Universitas Musamus. Mustek Anim Ha, $\quad 8(2), \quad 112-120$. https://doi.org/10.35724/mustek.v8i2.2531

Yasdomi, K., Rifqi, M., Maradona, H., \& Kurniawan, M. H. D. H. (2019). SISTEM PENDUKUNG

KEPUTUSAN PEMILIHAN MAHASISWA BERPRESTASI MENGGUNAKAN METODE SIMPLE ADDITIVE WEIGHTING ( SAW ) Sistem Pendukung Keputusan Pemilihan Mahasiswa Berprestasi Menggunakan Metode Simple Additive Weigthing ( SAW ). 05(01), 7-13. 